ANdreas Bärtels

\section{Wild- und Zieräpfel. Üppige Pracht für Gärten und Parks.}

Quelle \& Meyer Verlag, Wiebelsheim, 2021, 528 S., zahlreiche farbige Abbildungen, fest gebunden, ISBN 978-3-494-01830-0; 29,95 Euro

Äpfel kennt jeder, und wenn es nur die leckeren knackigen Früchte sind. Doch Äpfel und Apfelbäume bieten mehr. Neben einer Vielzahl an Sorten mit hoch geschätzten Früchten gibt es auch viele Wildarten und Kulturformen, die nicht als Obstgehölz gepflanzt werden. Sie sind Zierde im Garten wegen ihres üppigen Blütenflors im Frühling oder der leuchtend gelb bis rot gefärbten Früchte.

In den einführenden Kapiteln stellt der erfahrene Dendrologe und Autor zahlreicher Gehölzbücher Bärtels die Gattung Malus vor, wobei Morphologie, Systematik und Pflege der Apfebäume erklärt werden. Ferner wird die Verwendung als Zier- und Obstgehölz vorgestellt. Zudem gibt es einen Exkurs in die Literatur und wird u.a. der Apfel in Redensarten und Spruchweisheiten vorgestellt.
Den Großteil des Buches nimmt die Beschreibung der Arten und danach der vielen verschiedenen Sorten ein. Dabei werden Blüten sowie Früchte sehr großzügig mit relativ großen, brillanten Fotos abgebildet. Besonders schön zu betrachten sind bei einigen Arten die handkolorierten Zeichnungen von Äpfeln aus dem Archiv „Fischer“. Eine Tabelle am Ende des Buches mit den beschriebenen Sorten, dem entsprechenden Seitenverweis und Angaben zur Blütenfarbe erleichtert das Auffinden gewünschter Beschreibungen.

Das Buch ist allen zu empfehlen, die sich mit der Vielfalt der Gattung Malus als Obst- und Ziergehölz intensiver befassen möchten und vielleicht auch Tipps für die Pflanzung der passendsten Sorte für den gewünschten Zeck erhalten möchten. Je nach Größe des Grundstückes bzw. des Gehölzes bieten sich Apfelbäume auch für einen naturnahen Gartenzweck an. Die Blüten sind schon früh im Jahr eine gute Nahrungsquelle für Insekten, im Herbst werden die Früchte gern von Vögeln gefressen. Für den Umfang des Buches ist der Preis durchaus angemessen .

Dr. Hilke Steinecke 